\title{
ASPECTOS DOS LÍQUIDOS CEFALORRAQUIDIANOS NAS MENINGITES BACTERIANAS
}

\author{
Claudia E. O. Pires de Campos, Nilse N. Q. Santos, Mirian N. Takahashi, \\ Isabel E. Kawamura, Silvia V. Damião, Tuba M. Kushnaroff e \\ Evanil Pires de Campos
}

\begin{abstract}
Foram colhidos 1815 liquidos cefalorraquidianos de doentes internados commeningite, no Hospital Emilio Ribas, São Paulo, durante os meses de maio a outubro de 1989. Neisseria meningitidis $56 \%$, dos quais $44 \%$ do tipo $B$; Haemophilus influenzae $17 \%$, sendo $72 \%$ isoladas de neonatos até 3 anos; Streptococcus pneumoniae $14 \%$, dos quais $60 \%$ isolados de recém nascidos a 1 ano de idade. O estudo citoquímico liquórico mostrou: celularidade: global $>$ $500 \mathrm{cel} / \mathrm{mm}^{3}$ e especifica $>70 \%$; proteinas $>90 \mathrm{mg} / \mathrm{dl}$ e glicose $<45 \mathrm{mg} / \mathrm{dl}$ em $90 \%$ e celularidade $<500 \mathrm{cel} / \mathrm{mm}^{3}$ entre 2 a $6 \%$ nos três tipos de meningites avaliadas. A bacterioscopia e o citoquímico liquóricos foram decisivos na orientação da cultura e preditivos no diagnóstico etiológico dessas meningites (Teste de Goodman).
\end{abstract}

Palavras-chaves: Liquor. Meningites bacterianas.

Surtos de meningite ocorrem em intervalos aproximados de 8 a 12 anos e originam-se na estação seca e terminam quando se inicia a fase de chuva ${ }^{13}$. Fato semelhante se observa no Brasil pelas condições climáticas, sócio-econômicas precárias e pela miséria existente. Tais fatores predisponentes facilitam a manutenção e a disseminação da meningite nas crianças que vivem nas favelas da cidade de São Paulo, Brasil ${ }^{114}$. Estas são atingidas pela Neisseria meningitidis do tipo $\mathrm{B}$ e $\mathrm{C}$ que coexistem nos portadores maiores de 21 anos dessa comunidade $^{14581012131415}$.

A maioria das epidemias de meningite meningocócica está ligada à Neisseria meningitidis do tipo $\mathrm{A}$, cuja rápida disseminação atinge, principalmente, as crianças ${ }^{1} 4 \quad 5 \quad 8 \quad 10131415$. A infância é, portanto, dizimada nas epidemias de meningite pneumocócica e, principalmente, meningocócicas e por hemófilos, ocorridas nos países designados subdesenvolvidos ${ }^{14568}$.

A par disso, resolveu-se estudar o comportamento do líquido cefalorraquidiano (LCR) das meningites bacterianas mais isoladas de pacientes internados no Hospital Emílio Ribas de São Paulo, Brasil, durante o surto ocorrido em 1989.

Hospital Emílio Ribas, São Paulo, SP e Instituto de Biociências e Universidade Estadual Paulista, Botucatu, SP.

Endereço para correspondência: Dra. Claudia E. O.P. Campos.

R. Joāo Rafael 350, 18602-220 Botucatu, SP, Brasil.

Recebido para publicação em 18/01/94.

\section{MATERIAL ¿̀ MÉTODOS}

\section{Pacientes}

Foram avaliados 1815 líquidos cefalorraquidianos (LCR) de recém nascidos a maiores de 26 anos de idade, sendo 1089 do sexo masculino e 726 do feminino. Foram colhidos, quando possível, $5 \mathrm{ml}$ de LCR e enviados imediatamente ao laboratório clínico do hospital e submetidos aos seguintes procedimentos para o isolamento do agente etiológico: morfologia coloração de esfregaços em lâminas e corados pelo método de Gram e pelo método da Tinta da China nos casos sugestivos de meningite não bacteriana; isolamento e identificação - utilizaram-se normas preconizadas por Cowan \& Steel ${ }^{2}$, Edwards \& Ewing $^{3}$ e Lennette ${ }^{11}$ para identificação de bactérias aeróbicas e anaeróbicas facultativas. $O$ isolamento foi realizado em ágar chocolate (Mueller Hinton ágar - "Difco" acrescido de 10\% de sangue de carneiro desfibrinado a quente). Após a semeadura do LCR nas placas de ágar chocolate, estas eram colocadas em jarras de Gaspak com envelopes geradores de $10 \%$ de $\mathrm{CO}_{2}$, com o objetivo de permitir o crescimento da maioria das bactérias patogênicas. A identificação sorológica das amostras de Neisseria meningitidis foi realizada no Instituto Adolfo Lutz de São Paulo, SP. 
Campos CEOP, Santos NNQ, Takahashi MN, Kawamura IE, Damião SV, Kushnaroff TM, Campos EP. Aspectos dos liquidos cefalorraquidianos nas meningites bacterianas. Revista da Sociedade Brasileira de Medicina Tropical 27:87-91, abr-jun, 1994.

\section{Interpretação etiológica das meningites}

1. Meningococos: Neisseria meningitidis (NM), identificada do LCR ou positivo ao antígeno específico aplicado no LCR ou soro e/ou pela visualização de diplococos gram negativos, em lâminas e/ou pelo isolamento da bactéria.

2. Pneumococos: Streptococcus pneumoniae (SP), isolado do LCR ou soro e/ou diplococos gram positivos em forma de "chama de vela" visualizados em lâminas.

3. Hemófilos: Haemophilus influenzae (HI), isolado do LCR ou através da contra-imune eletroforese realizada com anti-soro específico e a presença de bastonetes gram negativos visualizados em lâminas.

\section{Estudo citoquímico}

No estudo citoquímico do fluido cerebrospinal, foi utilizada a Câmara de Fucks Rosenthal para contagem e avaliação da celularidade global e centrifugação, sendo as lâminas coradas pelo método de Leishman para contagem específica e observação das células à microscopia.

Os seguintes métodos: Turbidimetria (ácido tricloroacético) para as proteínas e o método enzimático para a glicose foram aplicados no estudo bioquímico do LCR. Aspecto turvo/purulento com leucocitose > 500 células $/ \mathrm{mm}^{3}$; neutrófilos :> $70 \%$; glicose $<45 \mathrm{mg} / \mathrm{dl}$ e diagnóstico pela bacterioscopia e/ou cultura ou métodos imunológicos, definiu meningite bacteriana aguda.

\section{Análise estatística}

Empregou-se o teste de Goodman ${ }^{7}$ nos achados bacteriológicos e citoqufmicos dos LCR, colhidos no momento da internação dos doentes com meningite bacteriana.

\section{RESULTADOS}

As bactérias NM, SP e HI, isoladas em $24 \%$ dos LCR, atingiram ambos os sexos, desde recém nascidos até maiores de 26 anos, na relação de $60 \%$ e $40 \%$, respectivamente, para o sexo masculino/ feminino. No entanto, $18 \%$ das amostras de NM e $35 \%$ das SP foram isoladas de pacientes com idade igual ou superior a 19 anos. Houve predomínio do sexo masculino ( 52 casos) em relação ao feminino (29 casos) na meningite por HI.

Os $249(56 \%)$ casos de meningites por NM, 78 (17\%) casos de HI e os 61 (14\%) casos de SP foram os mais isolados em $76 \%$ das crianças recémn nascidas até 12 anos, nas quais a NM tipo B surgiu em $56 \%$ de neo-natos até 6 anos e em $22 \%$ da idade superior a 18 anos. A distribuição mensal dos sorotipos revelou predomínio de isolamento da NM tipo $B$ em relação a tipo C e tipo W135 (Figura 1). A SP foi isolada em $60 \%$ das crianças com até 1 ano; a HI em $72 \%$ na idade de dias a 3 anos.

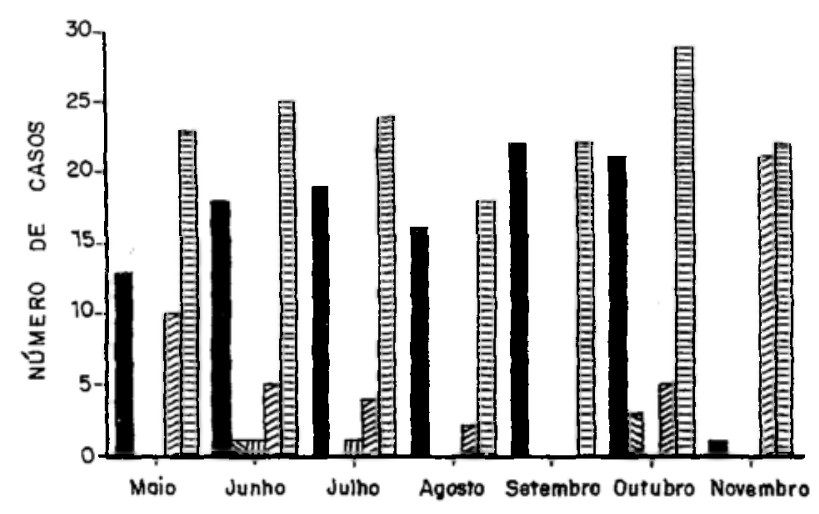

-

S.I. - Sem informaģăo

Figura 1 - Distribuiçãomensaldos sorotipos de Neisseria meningitidis. 
Campos CEOP, Santos NNQ, Takahashi MN, Kawamura IE, Damião SV, Kushnaroff TM, Campos EP. Aspectos dos líquidos cefalorraquidianos nas meningites bacterianas. Revista da Sociedade Brasileira de Medicina Tropical 27:87-91, abr-jun, 1994.

Das 1815 amostras de LCR colhidas, outras bactérias (bastonetes gram negativos $-4,9 \%$, outros cocos gram positivos $-5,1 \%$ ) e os fungos isolados (3\%), principalmente Cryptococcus sp, não foram incluídos no presente trabalho (Tabela 1).

Os três agentes bacterianos apresentaram distribuição semelhante nas faixas etárias de 2 a 3 e de 3 a 18 anos, sendo, porém, as HI e SP mais freqüentes na idade de dias até o primeiro ano de vida.

O aspecto turvo e/ou purulento do LCR foi observado, respectivamente, em $79 \%, 73 \%$ e $70 \%$ das amostras de NM, SP e HI isoladas das meningites.

A análise estatística pelo método de Goodman ${ }^{7}$, aplicada no estudo citoquímico do LCR revelou: celularidade global $>500$ células $/ \mathrm{mm}^{3}$ e específica $>70 \%$; proteínas $>90 \mathrm{mg} / \mathrm{dl}$ e glicose $<45 \mathrm{mg} / \mathrm{dl}$

Tabela 1 - Número e porcentagens de bactérias mais isoladas nas meningites frente à bacterioscopia e à cultura.

1. N. meningitidis - 249 (56\%) casos dos 443

dos 1.815 correspondem a $13 \%$

desses 249 casos tivernos:

cultura + e bacterioscopia $+=135(54 \%)$

cultura - e bacterioscopia $+=98(39 \%)$

cultura + e bacterioscopia - $=15(7 \%)$

2. H. influenzae - 78 (17\%) casos dos 443

dos 1.815 correspondem a $4,2 \%$

desses 78 casos tivemos:

cultura + e bacterioscopia $+=65(84 \%)$

cultura + e bacterioscopia - $=12(15 \%)$

cultura - e bacterioscopia $+=1$ (1\%)

3. S. pneumoniae - 61 (14\%) casos dos 443

dos 1.815 correspondem a 3,3\%

desses 61 casos tivemos:

cultura + e bacterioscopia $+=53(86 \%)$

cultura - e bacterioscopia $+=6(10 \%)$

cultura + e bacterioscopia - $=2(4 \%)$

Total de liquor estudado $=1.815 ;$ total de liquor positivo $=443(24 \%)$ relacionados em $90 \%$ aos três agentes bacterianos (Tabela 2).

No entanto, a celularidade global e específica inferior a 500 células $/ \mathrm{mm}^{3}$ foi eventual ( 2 a $6 \%$ ), enquanto a proteína do LCR superior a $90 \mathrm{mg} / \mathrm{dl}$ foi mais significativa na meningite pneumocócica nas primeiras horas da internação (Tabela 3).

A bacterioscopia e a cultura positivas foram relacionadas nas diversas faixas etárias, todavia a cultura foi mais positiva na idade de $0-1$ ano para as três bactérias; de 4 a 12 anos, NM foi semelhante à HI e de 2 a 3 anos houve maior freqüência de HI identificados (Tabela 4).

A bacterioscopia e a cultura positivas $(\mathrm{NM}=54 \% ; \mathrm{SP}=86 \%$ e $\mathrm{HI}=84 \%)$ foram coincidentes, porém, a bacterioscopia foi fundamental e decisiva na determinação da etiologia (principalmente para NM) nas meningites avaliadas.

Tabela 2 - Provas citoquímicas versus Neisseria meningitidis, Haemophilus influenzae e Streptococcus pneumoniae.

\begin{tabular}{|c|c|c|c|c|c|}
\hline Agente & $\begin{array}{l}\text { Celula- } \\
\text { ridade } \\
>1.000\end{array}$ & $\begin{array}{c}\text { Glico- } \\
\text { se } \\
<45\end{array}$ & $\begin{array}{c}\text { Proteí- } \\
\text { na } \\
>90\end{array}$ & $\begin{array}{c}\text { Neutró- } \\
\text { filo } \\
>70\end{array}$ & Total \\
\hline$N$. meningitidis & 230 & 229 & 230 & 230 & 243 \\
\hline H. influenzae & 49 & 50 & 49 & 49 & 65 \\
\hline S. pneumoniae & 34 & 36 & 34 & 34 & 61 \\
\hline
\end{tabular}

Total meningites

$\begin{array}{llllll}\text { bacterianas* } & 315 & 310 & 315 & 315 & 443\end{array}$

* Testes de Goodman

Tabela 3 - LCR: provas citoquimicas das Neisseria meningitidis tipo $B$.

\begin{tabular}{|c|c|c|c|c|c|}
\hline Amostra & $\begin{array}{l}\text { Celula- } \\
\text { ridade } \\
>500\end{array}$ & $\begin{array}{c}\text { Glico- } \\
\text { se } \\
<45\end{array}$ & $\begin{array}{c}\text { Proteí- } \\
\text { na } \\
>90\end{array}$ & $\begin{array}{c}\text { Neutró- } \\
\text { filo } \\
>70\end{array}$ & Total \\
\hline NM tipo B $110^{*}$ & 108 & 105 & 114 & 116 & 128 \\
\hline
\end{tabular}

* $N$. meningitidis total de isolamento $=128$ 
Campos CEOP, Santos NNQ, Takahashi MN, Kawamura IE, Damião SV, Kushnaroff TM, Campos EP. Aspectos dos liquidos cefalorraquidianos nas meningites bacterianas. Revista da Sociedade Brasileira de Medicina Tropical 27:87-91, abr-jun, 1994.

Tabela 4 - Distribulição etária versus exames bacterioscópicos e culturas nos LCR de 1815 pacientes.

\begin{tabular}{|c|c|c|c|c|c|c|c|c|c|}
\hline \multirow[b]{2}{*}{$\begin{array}{l}\text { Idade } \\
\text { (anos) }\end{array}$} & \multicolumn{3}{|c|}{$\begin{array}{c}N . \text { meningitidis } \\
(249)\end{array}$} & \multicolumn{3}{|c|}{$\begin{array}{c}\text { H. influenzae } \\
(78)\end{array}$} & \multicolumn{3}{|c|}{$\begin{array}{c}\text { S. pneumoniae } \\
(61)\end{array}$} \\
\hline & $\begin{array}{l}\text { bact }+ \\
\text { cult }+\end{array}$ & $\begin{array}{l}\text { bact - } \\
\text { cult }+\end{array}$ & $\begin{array}{c}\text { bact }+ \\
\text { cult - }\end{array}$ & $\begin{array}{l}\text { bact }+ \\
\text { cult }+\end{array}$ & $\begin{array}{l}\text { bact - } \\
\text { cult }+\end{array}$ & $\begin{array}{c}\text { bact }+ \\
\text { cult - }\end{array}$ & $\begin{array}{l}\text { bact }+ \\
\text { cult }+\end{array}$ & $\begin{array}{l}\text { bact - } \\
\text { cult + }\end{array}$ & $\begin{array}{c}\text { bact }+ \\
\text { cult - }\end{array}$ \\
\hline $0-3$ & 47 & 6 & 27 & 49 & 5 & 1 & 15 & - & 2 \\
\hline $4-12$ & 27 & 2 & 25 & 3 & 2 & - & 6 & 1 & 1 \\
\hline $13-18$ & 7 & 1 & 13 & 1 & 1 & - & 2 & - & - \\
\hline $19-25$ & 12 & 1 & 6 & - & 1 & - & 5 & - & 1 \\
\hline$>26$ & 13 & 1 & 11 & 2 & 1 & - & 13 & 1 & 1 \\
\hline SI & 29 & 4 & 17 & 10 & 2 & - & 12 & - & 1 \\
\hline Total* & 135 & 15 & 99 & 65 & 12 & 1 & 53 & 2 & 6 \\
\hline
\end{tabular}

bact $=$ bacterioscópico; cult $=$ cultura; SI $=$ sem informação de idade.

* Teste de Goodman

\section{DISCUSSÃO}

A incidência das meningites em países subdesenvolvidos parece ser semelhante às mais freqüentes descritas em nosso resultado 145101213 14. A maioria dos agentes etiológicos: NM, SP, eHI identificados, em nosso hospital, coincidiu com dados da literatura 145689101213141516 .

A distribuição etária e a relação masculino/ feminino parecem seguir os preceitos da literatura, a saber, uma maior incidência na infância como ocorre, habitualmente, nos surtos epidêmicos ${ }^{1456}$ 8101213141516 .

O maior número de casos (SP e HI), na idade superior a 19 anos, e o predomínio do sexo masculino na HI sugeriram maior exposição extradomiciliar dos portadores, além da possível contribuição do fator hormonal masculino no aparecimento dessas meningites $^{4} 581013$. As meningites por SP e HI parecem seguir as mesmas características epidemiológicas da doença NM1 5810131416 .

Apesar do predominio, em nossa casuística, de NM tipo B no surto de meningite de 1989 , sabe-se que em cada 5 a 10 anos surgem, em maior proporção, as NM tipo Ae NM tipo C nas populaçôes estudadas ${ }^{4}$ 581013 . A exemplo de nosso trabalho (isolamento da NM em diversos meses) a estação do ano, ora quente, ora fria, foi acompanhada de modificações da umidade e do mau tempo que obrigou a aglutinação domiciliar nas favelas ${ }^{15} 101314$. A NM tipo $\mathrm{B}$ e o $\mathrm{HI}$ atingiram, respectivamente, $56 \%$ e $70 \%$ das crianças ( 0 a 7 anos) e, respectivamente, $22 \%$ e $7 \%$ dos adultos maiores de 18 anos. Estes dados, aliados às condições sócio-econômicas expostas, demonstraram a facilidade da aquisição da doença menigítica ${ }^{14581014}$. A NM tipo B foi observada em $61 \%$ da população do Reino Unido (surto de 1987) onde melhores condições habitacionais estão presentes. Além disso, os sorotipos $\mathrm{A}$ e $\mathrm{C}$ predominam após o surto inicial da NM tipo B nas meningites basterianas ${ }^{14} 810121314$ 15 .

Os fatores prognósticos dos LCR foram importantes e decisivos na avaliação da gravidade das meningites estudadas 4591012131416 .

$\mathrm{O}$ aspecto turvo/purulento, presente em 70 a $79 \%$, e os fatores prognósticos positivos, em $75 \%$ dos doentes internados, auxiliaram no diagnóstico das meningites bacterianas consideradas ${ }^{4} 56121314$ 16 .

Sabe-se que a glicose, o lactato e atualmente TNF do LCR permitem afirmar a etiologia bacteriana da meningite 456101216 . No entanto, o aspecto turvo e/ou purulento; a celularidade $>500$ células $/ \mathrm{mm}^{3}$ e a bacteriologia do líquor definem, em nosso meio, a presença da meningite bacteriana, achados estes, condizentes com os da literatura 145 691012131416 . A bacteroscopia e a cultura positivas foram importantes e significativas no diagnóstico etiológico das meningites 451012131416 . Além disso, a bacterioscopia do líquor foi fundamental e indicativa para a cultura do agente bacteriano na doença menigítica 591012131416 .

A elevada negatividade da cultura $(76 \%)$ nas meningites foi devido, em parte, ao uso prévio de antimicrobiano e nessa condição, a evolução silente 
Campos CEOP, Santos NNQ, Takahashi MN, Kawamura IE, Damião SV, Kushnaroff TM, Campos EP. Aspectos dos liquidos cefalorraquidianos nas meningites bacterianas. Revista da Sociedade Brasileira de Medicina Tropical 27:87-91, abr-jun, 1994.

da doença menigítica 59101316 .

As demais bactérias gram negativas foram isoladas, principalmente, no primeiro trimestre de vida das crianças internadas com meningite a exemplo, dos resultados obtidos em outras investigações 168121314 .

O nosso estudo permitiu concluir que: as três bactérias: NM (76\%), HI (72\%) e SP (60\%) foram predominantes nas meningites bacterianas da infância $^{14213}$. A NM tipo B foi predominante (67\%), enquanto as do NM tipo C e W135 foram, eventualmente, isoladas nos doentes internados 148 13. O estudo citoquímico liquórico e a bacterioscopia foram fundamentais no diagnóstico etiológico das meningites bacterianas 4101213141516 .

\section{SUMMARY}

Samples of 1815 cerebrospinal fluid (CSF) were studied in a meningitis outbreak during 1989 in São Paulo, Brazil. Neisseria meningitis $56 \%$ with $44 \%$ type $B$, Haemophilus influenzae $17 \%$, from which $72 \%$ in children (days to 3-year old) and Streptococcus pneumoniae $14 \%$ from which $60 \%$ in children (day to 1 year old) of $443(24 \%)$ of all strains. Cytochemistry study showed: purulent or turbidity aspects in 70 to $79 \%$ positive bacterioscopy or culture of CSF; white cells

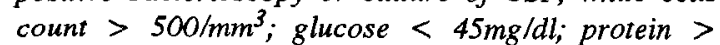
$90 \mathrm{mg} / \mathrm{dl}$ in $90 \%$ of all patients. We concluded that: CSF prognostic factors: (aspect and cytochemistry) were correlated with bacterial meningitis. Bacterioscopy and positive cultures were correlated to NM, SP and HI isolation from these patients (Goodman Test.)

\section{Key-words: Cerebrospinal fluid. Bacterial} meningitis.

\section{REFERÊNCIAS BIBLIOGRÁFICAS}

1. Bryan J, Silva $\mathbf{H}$, Tavares A, Rocha $\mathbf{H}$, Sheld W. Etiology and mortality of bacterial meningitis in northeastern Brazil. Review of Infectious Diseases 12:128-135, 1990.

2. Cowan ST, Steeel KJ. Manual of the identification of medical bacteria. $2^{\text {nd }}$ edition, Cambridge University p. 238, 1974.

3. Edward $\mathrm{DL}$, Ewing $\mathrm{NH}$. Identification of Enterobacteriacceae. $3^{\text {th }}$ edition, Burgess, Minneapolis p. 362, 1972.

4. Feigin RD. Bacterial meningitis beyond the neonatal period. In: Feigin RD, Cherry JD (eds) Textbook of Pediatric Infectious Diseases. Saunders, Philadelphia p. 916, 1992.

5. Girgis NI, Sppel JE, Kilpatrick ME, Sanborn WR,
Mikai IA, Cross E, Erian MW, Sultan Y, Farid Z. Meningitis and encephalitis at the Abbassia Fever Hospital, Cairo, Egypt, From 1966 to 1989. The American Journal of Tropical Medicine and Hygiene 48:97-107, 1993.

6. Glimaker $M$, Kragsberg P, Forsgeen $M$, Olcen P. Tumor necrosis factor (T.N.F $\alpha$ ) in cerebrospinal fluid from patients with meningitis of different etiologies: high levels of TNF $\alpha$ indicate bacterial meningitis. The Journal of Infectious Diseases 167:882-889, 1993.

7. Goodman LA. Simultaneous confidence intervals for contrast among multinomial populations. Annals of Matematical-Statistic 35:716-775, 1964.

8. Greenwood BM, Greenwood AM, Bradley AK. Factors influencing susceptibility in meningococcal disease during an epidemie in the Gambia - West Africa. Journal of Infectious 14:167-184, 1987.

9. Kilpatrick M, Mikail I, Girgis N. Negative culture of cerebrospinal fluid in partially treated bacterial meningitis. Tropical Geographic Medicine 39:345$349,1987$.

10. Kumar P, Verma IC. Antibiotic therapy for bacterial meningitis in children in developing countries. Bulletin of the World Health Organization 71:183188, 1993.

11. Lennette EH, Ballows A, Hausler WJ, Shadomy HJ. Manual of clinical Microbiology. American Microbiology Society, $4^{\text {th }}$ edition, Washington DC, 1985.

12. Lindquist $L$, Linne $T$, Hansson LO, Kalin $M$, Axelsson G. Value of cerebrospinal fluid analysis in the differential diagnosis of meningitis a study in 710 patients with suspected central nervous system infection. European Journal of Clinical Microbiology Infectious Diseases 7:374-380, 1988.

13. Pinner RW, Onyango F, Perkins BA, Mirza NB, Ngacha DM, Reever M, DeWitt W, Njeru E, Agata NN, Broome CV and Kenya Centers for Disease Control (C.D.C.) Meningitis Study Group. Epidemic meningococcal disease in Nairobi, Kenya, 1989. The Journal of Infectious Diseases 166:359-364, 1992.

14. Stocco JM, Porfirio FMV, Carvalho VO, Nunes FF, Santos NNQ, Campos CEOP, Schmal MR, Kuschnaroff TM. Septicemia com púrpura por Haemophilus influenzae e sua semelhança com meningococcemia. In: XXVI Congresso da Sociedade Brasileira de Medicina Tropical, Natal p.196, 1990.

15. Tzanakaki G, Blackwell CC, Kremastion J, Weir DM, Montes A, Fallon BJ. Serogroups; serotypes and subtypes of Neisseria meningitis isolated from patients and carrier in Greese. Journal of Medical Microbiology 38:19-22, 1993.

16. Wright PW, Avery WG, Ardill WD, McCarty JW. Initial clinical assessment of the comatose patient: cerebral malaria vs meningitis. Pediatric Infectious Diseases Journal 12:37-41, 1993. 